\title{
Avaliação discente de um Curso de Tecnologia em Gestão Pública à luz da Teoria da Interação a Distância
}

Alexandre Motta

José André Peres Angotti

\begin{abstract}
Resumo
O trabalho consiste em uma reflexão sobre a Educação a Distância, evidenciando estudos de Michael Moore e a teoria da Interação a Distância, que concebe a modalidade não apenas como separação geográfica entre aprendizes e instrutores, contudo, como um conceito pedagógico. Diante dos desafios da ação docente, buscamos a conciliação entre liberdade individual e cooperação exigida em cursos on line. A avaliação realizada pelos alunos do Curso Superior de Tecnologia em Gestão Pública, que está sendo oferecido pelo Instituto Federal de Educação, Ciência e Tecnologia de Santa Catarina na modalidade a distância, é priorizada. Em pesquisa de campo abrangendo seis pólos do curso, vinculados ao sistema Universidade Aberta do Brasil, investigam-se as relações professor-aluno com o intuito de promover novas formas de interações ao longo do curso, de acordo com a teoria discutida.
\end{abstract}

Palavras-chave: Educação à Distância; interação; diálogo; autonomia

\section{Abstract \\ Student evaluation of a course in Public Management Technology to the Theory of Distance Interaction}

The work consists of a reflection on the Distance Learning, showing Michael Moore's studies and the theory of the Interaction Distance, which sees the modality not only as geographical separation between learners and instructors, however, as an educational concept. Faced with the challenges of teaching action, we seek to reconcile individual freedom and cooperation required in online courses. The evaluation made by students of the Course of Technology in Public Management, which is being offered by the Federal Institute of Education, Science and Technology of Santa Catarina in the distance mode is prioritized. In 
field research covering six clusters of the course, tied to the system Open University of Brazil, it investigates the teacher-student relationships in order to promote new forms of interactions throughout the course, according to the theory discussed.

Keywords: Distance learning; interaction; dialogue; autonomy

\section{Introdução}

As políticas educacionais cada vez mais apontam para a necessidade de ofertar educação para todos. Observa-se o surgimento de novas possibilidades que se configuram em diferentes modos de ingresso, flexibilizam-se organizações curriculares, criam-se as possibilidades de educação a distância, implementam-se propostas para todas as idades, entre outras opções.

Este trabalho aborda a modalidade de educação a distância (EaD) de uma instituição pública de ensino, o Instituto Federal de Educação, Ciência e Tecnologia de Santa Catarina (IF-SC), que não tem como finalidade única esta forma de ensino e dispõe de um Curso Superior de Tecnologia em Gestão Pública (CSTGP) iniciado em 2007, além de cursos de especialização.

Como objetivo, tem-se uma proposta de mudança do que está posto no âmbito dos cursos técnicos e alguns cursos tecnológicos do IF-SC; sendo que a visão de educação baseada na aprendizagem mediada pelas tecnologias, tem sido objeto de estudo de alguns pesquisadores da instituição para o desenvolvimento da EaD.

O CSTGP do IF-SC contemplado no primeiro edital do Sistema Universidade Aberta do Brasil (UAB) foi estruturado em cinco módulos interligados visando qualificar gestores públicos. O curso, ministrado em ambiente virtual, oferece aos alunos ferramentas e metodologias pedagógicas pouco utilizadas pelos docentes da instituição no ensino presencial.

A EaD considerada por André (2009) uma alternativa viável para um país como o Brasil, com uma enorme extensão territorial e a falta de igualdade na distribuição de oportunidades educacionais, comprovadas nos índices estatísticos, pode atender a uma demanda significativa de profissionais que ficam à margem de possibilidades de formação, capacitação e aperfeiçoamento.

Assim o artigo especifica as ações que deverá o professor adotar para promover a interação dos alunos nesta modalidade de ensino, valendo-se da Teoria da Interação a Distância, que segundo Moore e Kearsley (2007), trata do espaço psicológico e de comunicação que precisa ser atravessado, um espaço de potencial desentendimento entre professores e alunos, de forma que a distância possa ser suplantada, incluindo-se elementos diferenciadores no processo de ensino. 


\section{Análise Histórica}

Cabe iniciar uma discussão sobre a idéia de ensino adotada desde os primórdios da colonização, pelos jesuítas, que segundo Miorim (1995), o ensino brasileiro foi por mais de duzentos anos dominado quase que exclusivamente pelos padres da Companhia de Jesus. Como a maior questão da catequese era a conversão do gentio à religião católica, a relação educadoreducando começa marcada pelo autoritarismo e sentimento de superioridade da raça branca, colonizadora. Neste cenário surgem os grandes princípios da prática tradicional de ensino: o educador é o centro do processo de ensino; ele é o detentor do conhecimento que vai ser repassado e como tal não lhe cabe aceitar críticas ou questionamentos sobre o que e como ensina; o educando é o objeto a ser moldado e deve se submeter ao ensino do educador.

Miorim (1995) aponta ainda os finais do século XVIII e começos do século XIX para o florescimento de novas bases para a educação - o Movimento da Escola Nova. Tendo suas raízes fundamentadas no trabalho de grandes educadores europeus como Pestalozzi, Herbart, Fröebel (Monroe apud Vilarinho, 2008), veio a se expressar com mais clareza, no início do século XX, nas idéias de Dewey, Kilpatrick, Montessori, Decroly, Cousinet (Gadotti apud Vilarinho, 2008). Educadores brasileiros como Anísio Teixeira e Lourenço Filho, influenciados pelo pensamento de Dewey, dão uma grande contribuição à "desestabilização" de conceitos defendidos pelo coletivo até então vigente. Surgem novos princípios para o ensino-aprendizagem: o aluno passa a ser o centro do processo de ensino; o conhecimento não pode ser dado; ele é resultado do esforço do aprendiz sobre o objeto de estudo; o professor passa a ser orientador da aprendizagem cabendo estimular, facilitar e criar condições para que a aprendizagem do aluno ocorra.

No final dos anos sessenta eram lançadas as bases para uma compreensão mais ampla da educação, nas suas múltiplas relações. Desde então, um conjunto de educadores, caracterizados como Progressistas, entre os quais se destaca Paulo Freire, por sustentar uma concepção na qual educador e educando aprendem juntos buscando contínuo aperfeiçoamento numa relação dinâmica que integra teoria e prática (Freire, 1999), colaboram para que haja uma consciência mais clara dos determinantes sócio-políticos da educação.

Neste sentido, eles têm trazido uma grande contribuição para o ensino e apontam para o conhecimento como uma atividade social/histórica. Diante do cenário apresentado e da necessidade do estabelecimento de relações significativas de aprendizagem no contexto de mudanças relacionadas às atividades de EaD, em especial no âmbito IF-SC, há a necessidade de focalizar o indivíduo numa aprendizagem interativa com outros indivíduos, na qual estão presentes características como aprendizagem individualizada, flexibilidade e autodesenvolvimento.

Para a oferta de educação na modalidade à distância, Kenski (2003) salienta que deva existir uma nova lógica para o ensino, alterações nos papéis dos professores e das escolas, na 
ampliação das possibilidades em outros espaços e no oferecimento de algo com qualidade em tempos e lugares diferenciados, centrando os esforços e decisões sobre o modelo de educação tecnológica que a instituição pretende oferecer e, sobretudo, a linha filosófica e o projeto pedagógico do curso a ser ofertado.

Para Moraes (1997), o sistema educacional convencional vem se modificando com o surgimento e crescimento das Tecnologias de Informação e Comunicação (TIC) e o avanço da Internet, passou-se a vislumbrar uma expansão ampla da educação, considerando que se trata de uma tecnologia de comunicação que teve seus custos reduzidos, passando a ser um meio dominante, podendo aumentar exponencialmente os resultados educativos, na medida em que cada meio corresponde a uma determinada linguagem, as quais integradas enriquecem o processo educacional.

$\mathrm{Na}$ EaD, em especial, o computador pessoal e o sistema de rede informacional, trazem uma nova discussão sobre o que ensinar, como ensinar e para que ensinar a distância. A relação professor-aluno é substancialmente alterada neste contexto. A atividade cognitiva não deve ocorrer de forma abstrata, individual, mas dentro de um coletivo, sem separar o homem da sua relação com as tecnologias e, sobretudo, com seus pares.

A EaD se valendo da tecnologia de rede, que trabalha com interfaces, pode estender o que ensinar de diferentes formas, tendo a conexão com a rede uma maior quantidade de aprendizados, a interface poderá abrir novas relações, com links, frases, textos, histórias, imagens, músicas, enfim, podendo contribuir para ampliar o campo das representações e organizações mentais do aprendiz.

As indagações acima englobam princípios de interatividade, transitoriedade do conhecimento, interdisciplinaridade, sendo a eles acrescida a autonomia; assim, o estudo destas relações necessita de teorias próprias para a modalidade a distância, passando por profundas mudanças se comparadas ao ensino presencial tradicional e, procurando alinhar-se à teorias e práticas que apontam para o conhecimento não como um processo individual.

\section{Teorias da Educação a Distância}

Perspectivas teóricas sobre educação a distância têm sido apresentadas durante os últimos trinta anos. Keegan (1996) identifica três posições teóricas, destacadas a seguir:

- Teorias da autonomia e independência;

- Teorias da industrialização;

- Teorias da interação e comunicação. 
Uma das primeiras idéias para construção de uma teoria específica para a EAD que fosse abrangente e descritiva ou que apresentasse uma generalidade suficiente para incluir muitas formas de educação, capaz de posicionar um programa nesta modalidade em relação a qualquer outro, desenvolveu-se nos trabalhos de Michael Moore ${ }^{1}$ e que desde 1986 vem sendo conhecida como teoria da Interação a Distância (apresentada no próximo item), na linha autonomia e independência.

Uma segunda corrente, aqui mencionada, está centrada em considerações de Peters (1983), aplicando a teoria da industrialização para estruturação da EAD, com princípios de racionalização, divisão de trabalho, produção em massa, sendo o processo de ensino gradualmente reestruturado através da mecanização crescente, emergindo as seguintes proposições:

- O desenvolvimento de cursos a distância é tão importante como o trabalho preparatório que ocorre antes do processo de produção;

- A eficácia do processo de ensino é particularmente dependente do planejamento e organização;

- Os cursos devem ser formalizados e as expectativas dos estudantes padronizadas;

- As funções dos docentes nesta modalidade devem mudar consideravelmente se comparadas com o ensino convencional;

- O ensino precisa concentrar os recursos disponíveis em uma administração centralizada.

A teoria da industrialização não parece aplicar-se em cursos com conferência via web, por exemplo, uma vez que o desenvolvimento de produtos em massa para um número elevado de alunos pode, segundo Paulsen (1993), reduzir as oportunidades de interação do aluno junto a professores e tutores, dado à redução de custos que precisa ser realizado num processo desta natureza.

Por último, a teoria da interação e comunicação deve, para Holmberg (1986), estabelecer um sistema de conversação didática para cursos à distância, ou seja, deve haver uma interação constante (conversa) entre professor, tutor, conselheiros, coordenadores e os alunos da modalidade. A utilização dos recursos computacionais em cursos de EAD pode, segundo os

${ }^{1}$ Publicou em 1972 a primeira obra teórica (em inglês) sobre educação a distância, responsável por cerca de 100 publicações e um número maior de apresentações importantes em mais de 30 países, evidencia conhecimento efetivo sobre ensino e treinamento em todas as tecnologias para grupos de especialistas e interessados (Moore e Kearsley, 2007).

R. B. E. C. T., vol 4, núm 1, jan./abr. $2011 \quad$ ISSN - 1982-873X 
autores da teoria, ser um excelente meio para facilitar uma conversação didática guiada entre estudantes e corpo docente.

\title{
Teoria da Interação a Distância
}

A teoria da Interação a Distância, segundo Moore e Kearsley (2007), combina um sistema "industrial" estruturado, que inclui planejamento sistemático, especialização da equipe de trabalho, produção em massa de materiais, automação, padronização e controle de qualidade, bem como utiliza um conjunto completo de TIC's na estruturação de cursos, com uma relação mais centrada no aluno e interativa do aluno com o professor, sendo que a distância passa a ser um fenômeno pedagógico e não apenas uma questão geográfica, procurando investigar o efeito que esta distância exerce no ensino e no aprendizado, na elaboração do currículo e do curso e na organização e gerenciamento do programa educacional.

\begin{abstract}
"A Interação a Distância é o hiato de compreensão e comunicação entre os professores e alunos causado pela distância geográfica que precisa ser suplantada por meio de procedimentos diferenciadores na elaboração da instrução e na facilitação da interação.... a interação implica a inter-relação do ambiente e das pessoas com os padrões de comportamento em uma situação. É a distância física que conduz a um hiato na comunicação, um espaço psicológico de compreensões errôneas potenciais entre os instrutores e os alunos, que precisa ser suplantado por técnicas especiais de ensino - isso é a Interação a Distância." (Moore e Kearsley, 2007, pág. 240)
\end{abstract}

Na elaboração de Moore a separação entre professores e alunos na EaD determina que os docentes planejem, apresentem, interajam e articulem outros processos de ensino, de modo diferente do ambiente presencial, ou seja, existe uma natureza especial no comportamento organizacional e de ensino que depende do grau de Interação a Distância; tais comportamentos recaem em dois conjuntos de variáveis denominados de diálogo e estrutura.

O diálogo é um termo usado para descrever interações de professor e aluno com uma determinada finalidade, sendo construtivo e valorizado por cada participante. Sua extensão e natureza são determinadas pela filosofia educacional dos responsáveis pela elaboração de um curso, pela matéria envolvida e por fatores ambientais (linguagem, meios de comunicação).

A estrutura, por sua vez, trata do conjunto de elementos usados na elaboração do curso, tais como: objetivos de aprendizado, temas do conteúdo, apresentações de informações, estudos de caso, ilustrações, exercícios e testes. Também é determinada pela filosofia da organização de 
ensino, dos professores e do nível acadêmico dos alunos, além dos aspectos ambientais já mencionados.

As perspectivas para a presença do diálogo e o nível de estrutura variam em função do curso, com os alunos recebendo orientação por meio da interação com seus professores; não havendo diálogo nem estrutura deverão decidir sobre suas estratégias de estudo com mais independência e responsabilidade, onde então se apresenta uma segunda dimensão do estudo a autonomia do aluno.

Para Moore e Kearsley (2007), o conceito de autonomia do aluno significa capacidades diferentes para tomar decisões a respeito de seu próprio aprendizado, como: desenvolver um plano pessoal de estudo, encontrar condições em ambiente comunitário ou de trabalho e decidir quando o progresso está satisfatório; assim se aceita a independência do aprendiz como um recurso valioso no processo ensino-aprendizagem e não como uma perturbação que precise ser controlada.

Diante das considerações de Moore e da necessidade de outra dimensão no processo de EaD, acredita-se em uma perspectiva de equilíbrio entre as variáveis de ensino e um maior exercício da autonomia, cabendo ressaltar que o professor pode definir estratégias adequadas para que fique evidenciada a importância de uma educação centrada no aluno.

\section{Estratégias do Professor na Interação}

Na seção acima, percebe-se a importância que as variáveis diálogo, estrutura e autonomia adquirem no âmbito da EaD, ressalta-se também o valor da comunidade virtual e do trabalho colaborativo, além de análises discursivas na fase de avaliação de cursos nesta modalidade educacional.

Neste contexto, as Novas Tecnologias de Informação e Comunicação transformaram a atividade do professor, gerando ferramentas que nos permitem trabalhar com os alunos nos ambientes virtuais de aprendizagem. O professor precisa transformar seu modo de dar aula, explorando as ferramentas que o ambiente oferece, criando novas estratégias de interação com os alunos.

O ambiente virtual de aprendizagem permite ao professor disponibilizar textos interativos e de configuração hipertextual, apresentando os temas a serem estudados; torna possível também a realização de diversas atividades como chat e fórum para debates e explicações.

Para que fique evidenciada a importância das ferramentas, o papel do fórum, por exemplo, torna-se muito importante na relação professor-aluno. Ao professor contribui para complementar as explicações que iniciou na apresentação da aula, além de possibilitar o esforço de aproximação entre teoria e prática, mediante a criação de questões contextualizadas. Para o aluno, cria-se um 
início para o diálogo (variável fundamental na teoria da Interação a Distância de Moore) que vai se desenvolvendo ao longo da semana entre os participantes da aula e tendo um aproveitamento que depende do quanto se quer acompanhar esse processo.

É papel do professor de educação a distância perceber que em uma mesma tarefa ele deverá conversar com seu aluno e dirigir o estudo, facilitar o aprendizado, esclarecendo dúvidas e dificuldades que forem aparecendo. Palloff e Pratt (2004) afirmam que existe uma modificação no equilíbrio de forças altamente necessária na aula on-line, isto é, uma divisão do poder do professor com seus alunos:

"Se o professor incentiva os alunos a trabalhar com seus colegas e incentiva aqueles que gravitam em torno do papel de gerentes do processo a exercitarem tal papel, a responsabilidade pelo gerenciamento da experiência de aprendizagem será compartilhada. Assim, uma experiência centrada no aluno resulta em uma sala de aula mais democrática." (p. 148)

O professor a distância trabalha centrado no aluno, no sentido de que precisa conhecer exatamente o que e como o seu aluno está aprendendo e que dificuldades ele está vivenciando.

A participação do aluno e as atividades avaliativas também dependem da estratégia do professor, elas precisam ser despertadas, cabendo ao professor modificar sua metodologia de trabalho, visando a construção da comunidade na sala de aula virtual, tentando reduzir o hiato de comunicação na EaD e apontado por Moore em sua teoria.

Os princípios envolvidos na modalidade são aqueles atribuídos a uma forma mais ativa de aprendizagem, com uma diferença: na educação a distância, deve-se prestar atenção ao desenvolvimento da sensação de comunidade entre os participantes do grupo a fim de que o processo seja bem-sucedido. A comunidade é o veículo através do qual ocorre a aprendizagem. Os alunos passam a depender uns dos outros para alcançar os resultados esperados e definidos pelo curso (Pallof e Pratt, 2002).

\section{o Curso Superior de Tecnologia em Gestão Pública}

Como aplicação da teoria da Interação a Distância, apresentamos um estudo relacionado com estratégias que estão sendo utilizadas na investigação das relações professor-aluno no Curso Superior de Tecnologia em Gestão Pública (CSTGP), em particular com a disciplina de Matemática Aplicada, que está sendo oferecido pelo programa Universidade Aberta do Brasil (UAB) mencionado no início deste artigo. 
O IF-SC é uma instituição pública e gratuita que tem por finalidade dar formação e qualificação para profissionais de diversas áreas nos vários níveis e modalidades de ensino, bem como realizar pesquisa e desenvolvimento de novos processos, produtos e serviços, em articulação com os setores produtivos e a sociedade.

A estrutura organizacional do IF-SC, bem como sua natureza, finalidade, características e objetivos seguem um padrão definido pelo Ministério da Educação para as instituições federais de educação tecnológica.

Neste contexto, o próprio Ministério, ao lançar o primeiro edital do Sistema UAB em 2005 para a implantação da primeira etapa da rede de pólos de apoio presencial e cursos ofertados por universidades federais, procurou oferecer cursos superiores para capacitação de dirigentes, gestores e trabalhadores em educação básica dos Estados, do Distrito Federal e dos Municípios e apoiar a pesquisa em metodologias inovadoras de ensino superior respaldadas em tecnologias de informação e comunicação (BRASIL, 2009).

Neste artigo são considerados resultados da turma de 2007 de Gestão Pública, cujo objetivo (conforme projeto pedagógico do curso) é oferecer ensino centrado no aprendiz e fundamentado no princípio da educação permanente. É utilizada uma plataforma de ensinoaprendizagem, que disponibiliza materiais didáticos e espaços de aprendizagem baseados na hipermídia, para possibilitar uma maior autonomia ao aluno em seu processo de aprendizagem.

Cabe iniciar uma discussão sobre a idéia de ensino que os estudantes do CSTGP adquiriram ao longo de sua vida acadêmica e, aqui percebida como uma influência que Kenski (2003), como muitos outros pesquisadores e docentes bem salientam como de "velhos hábitos", percebida e enfrentada no fórum da unidade curricular de Matemática Aplicada.

O pensar dos alunos se deve, em parte, por práticas educativas relatadas anteriormente por Miorim (1995), onde a relação professor-aluno foi marcada pelo autoritarismo e sentimento de superioridade, princípios que, não raro, ainda prevalecem em muitas práticas de ensino.

Dessa forma, neste novo contexto educacional, o professor procurou garantir o movimento, a manutenção do diálogo permanente, de acordo com o que acontece em cada momento, propondo situações-problema, desafios, reflexões, estabelecendo conexões entre o conhecimento adquirido e o pretendido.

Neste sentido, aplicam-se as recomendações de Moraes (1997), que indica como responsabilidade do docente a abertura e garantia do processo educacional, ao buscar e mediar as transformações, para que a interação professor-aluno não provoque o seu fechamento, através de uma mecanização da forma de pensar, da apresentação de verdades absolutas, ou de caminhos únicos para o desenvolvimento da aprendizagem. 
Cabe registrar que o IF-SC adotou a plataforma Moodle ${ }^{1}$ na proposta deste curso e que dispõe de um conjunto de ferramentas que podem ser selecionadas pelo professor, como o fórum, questionários, textos, vídeos, atividades complementares, links externos, permitindo publicar materiais de quaisquer tipos de arquivos, dentre outras funcionalidades.

Com a primeira turma (entrada em 2007), fez-se um levantamento exploratório por intermédio de questionário e avaliação de questões no fórum da disciplina - disponibilizada no ambiente virtual - com o objetivo de especificar as ações que deverá o professor adotar para promover a interação dos alunos nesta modalidade de ensino, identificando a presença das variáveis diálogo e estrutura de Moore, na teoria da Interação a Distância.

No plano metodológico, trabalharam-se os pressupostos de uma pesquisa aplicada quantitativa e qualitativa. A população foi constituída pelos alunos regularmente matriculados no CSTGP que ingressaram em 2007/2 (um total de 288 alunos ainda permanecia no curso, dos 300 que foram aprovados no vestibular), sendo a amostra definida pelos respondentes dos questionários (194 alunos) e fórum propostos.

\section{Resultados}

Alguns aspectos gerais que foram analisados (quantitativamente) nesta primeira etapa do curso estão presentes nas figuras 1, 2 e 3 e, que mostram quais as características do aluno que trabalhamos no CSTGP do IF-SC:

${ }^{1}$ O Moodle (Modular Object-Oriented Dynamic Learning Environment) é um ambiente de aprendizagem a distância desenvolvido em primeira versão pelo australiano Martin Dougiamas em 1999. Como plataforma livre e qualquer outro LMS (Learning Management System), o Moodle pode ser customizado pelos usuários, dispondo sempre de um conjunto de ferramentas que podem ser selecionadas pelo professor de acordo com seus objetivos pedagógicos. 


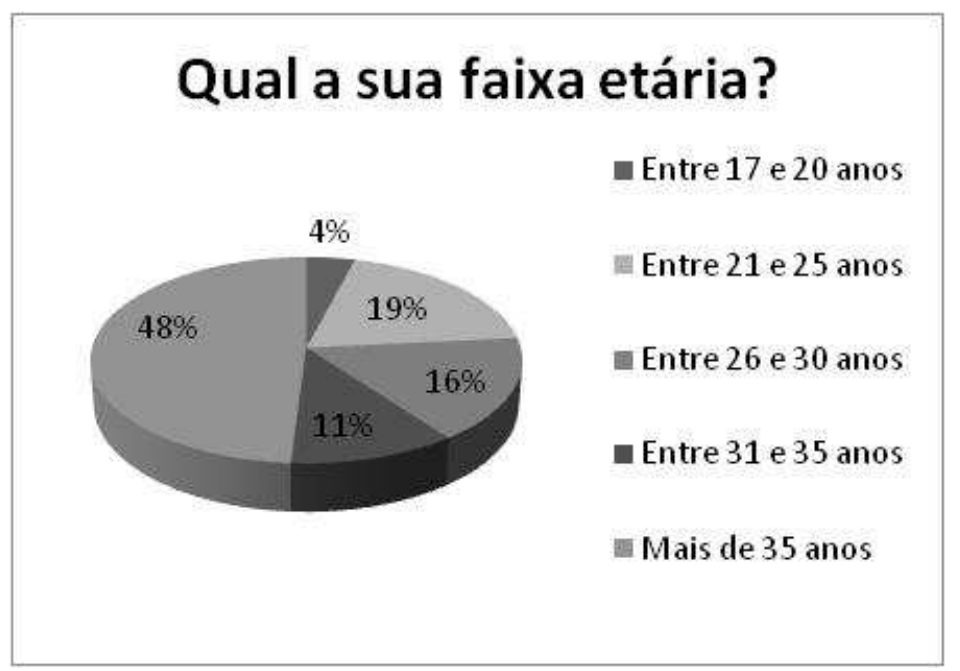

Figura 1: Faixa etária

\section{Você já participou de outro curso à distância?}

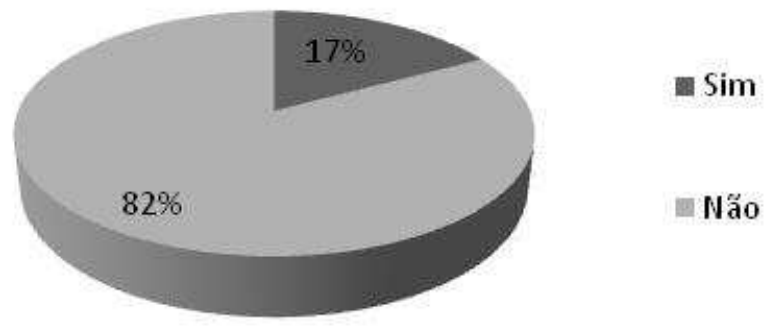

Figura 2: Participação na EaD 


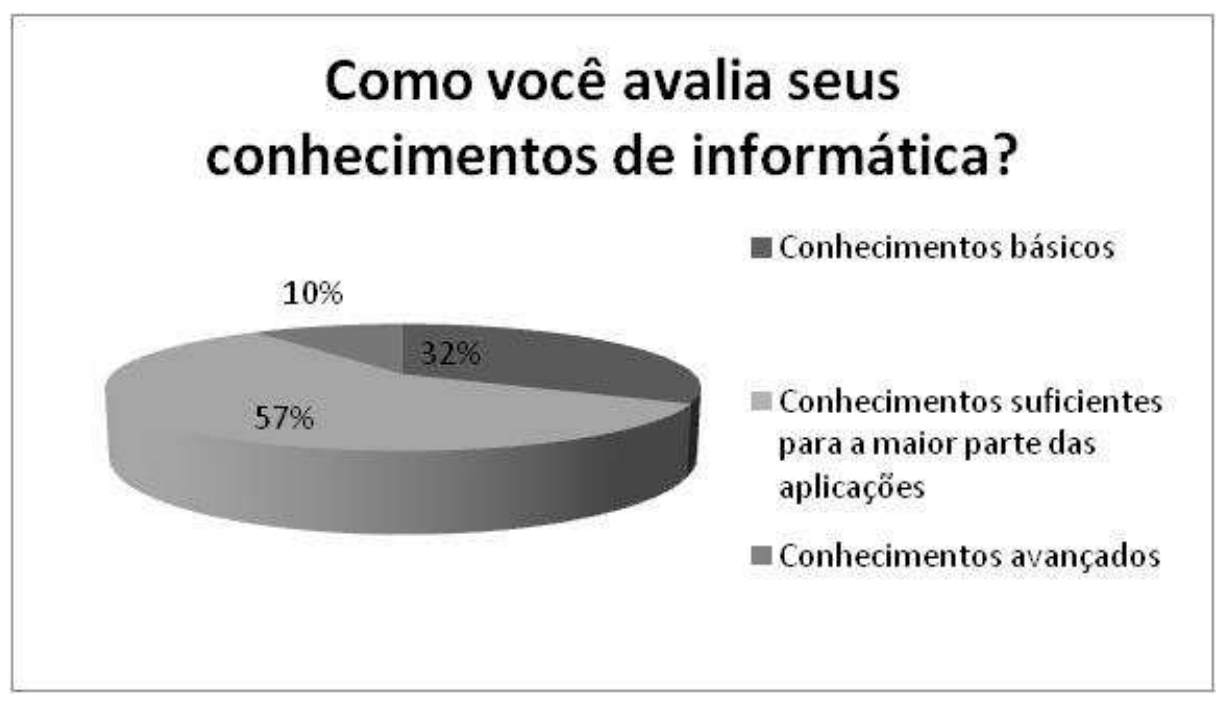

Figura 3: Conhecimentos de informática

A figura 1 apresenta 59\% dos alunos do CSTGP do IF-SC com mais de 31 anos de idade, acima dos tradicionais 18 ou 19 anos que são esperados no ingresso de cursos universitários. Esta idade reitera o fato de a EaD estar, de fato, oportunizando o acesso (figura 2) ao ensino, além da interiorização do mesmo, especialmente com o projeto da UAB do Ministério da Educação.

"Há um debate constante no mundo acadêmico sobre quem é levado a estudar on-line. Tem-se como um fato dado que os alunos que estudam on-line são adultos, pois essa espécie de aprendizagem, que se dá em qualquer lugar e a qualquer hora, permite-lhes continuar trabalhando em turno integral sem deixar de também dar atenção à família. O aluno on-line "típico" é geralmente descrito como alguém que tem mais de 25 anos, está empregado, preocupado com o bem-estar social da comunidade, com alguma educação superior em andamento, podendo ser tanto do sexo masculino quanto do feminino." (Gilbert apud Pallof e Pratt, 2004, pág. 23)

$\mathrm{Na}$ figura 3, 57\% dos alunos apresentam conhecimentos suficientes para a maior parte das aplicações que a EaD acaba por exigir, enfatizando que o acesso ao material didático (via ambiente), hipertexto, vídeo-aula, arquivos, fórum, planilhas eletrônicas e outras formas de interação que foram adotadas, dando ênfase à estrutura do curso, estavam sendo oportunizadas e utilizadas sem dificuldades maiores pelos acadêmicos (as unidades curriculares sobre Ambientes Virtuais, EaD e Informática já haviam sido ministradas em um período anterior à de Matemática Aplicada). 
Em relação à disciplina de Matemática Aplicada do CSTGP, algumas considerações foram feitas com relação ao ambiente virtual (vídeo-aula, hipertextos, links), material didático e desempenho do professor (interação direta com o aluno). Os resultados aparecem nas figuras 4 , $5,6,7$ e 8 .

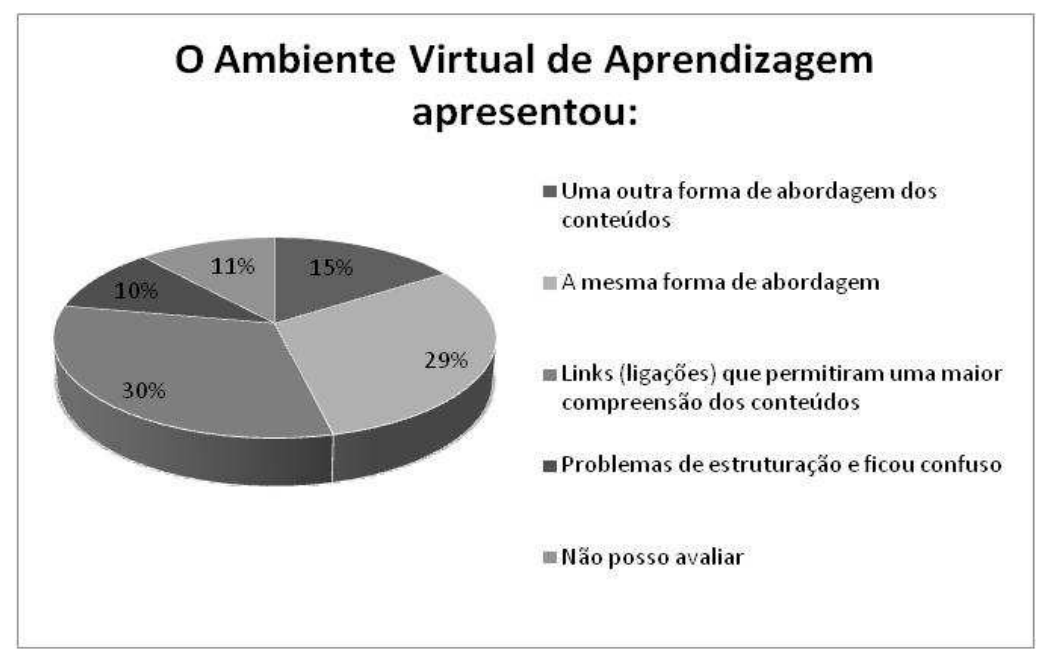

Figura 4: AVA de Matemática Aplicada

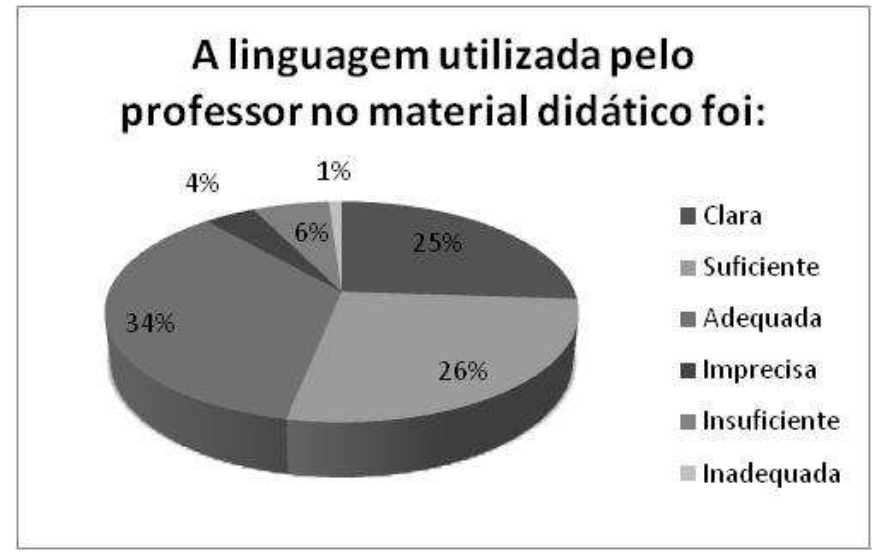

Figura 5: Linguagem utilizada

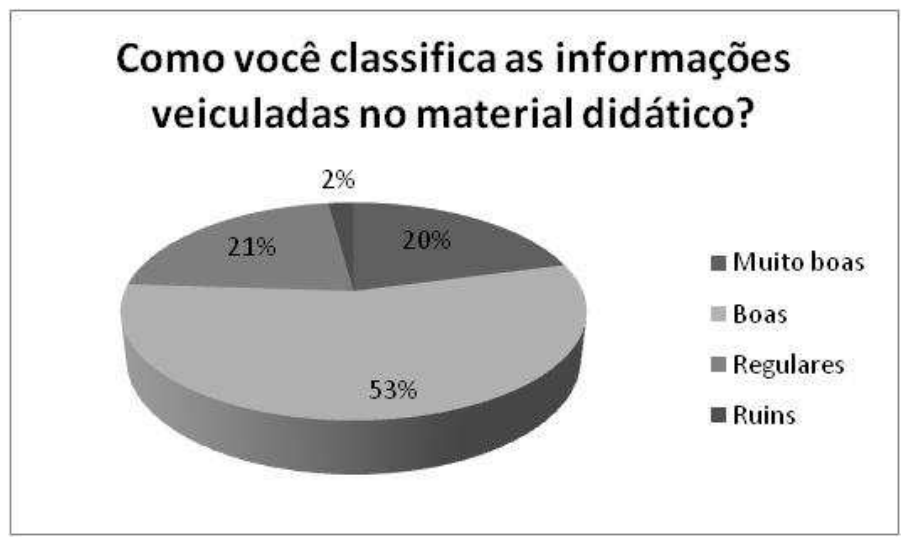


Figura 6: Informações do material didático

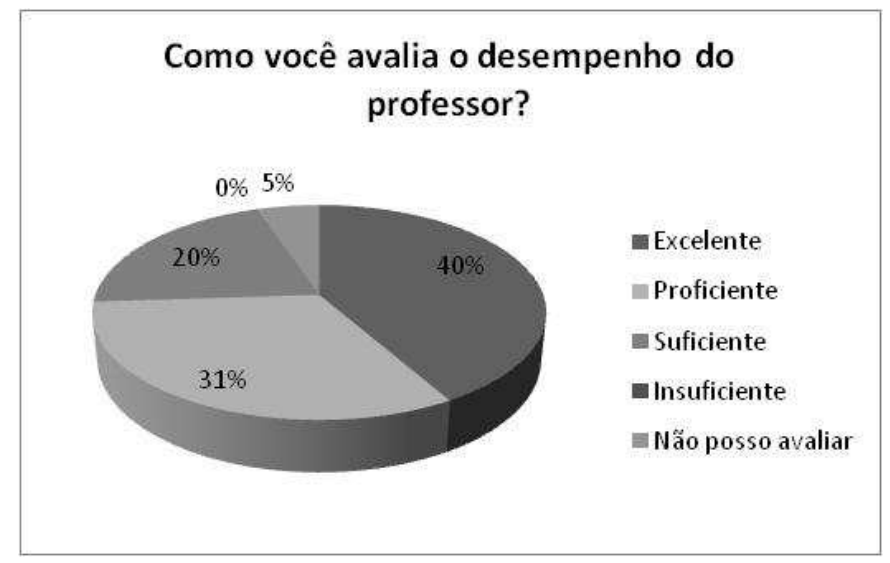

Figura 7: Desempenho do professor

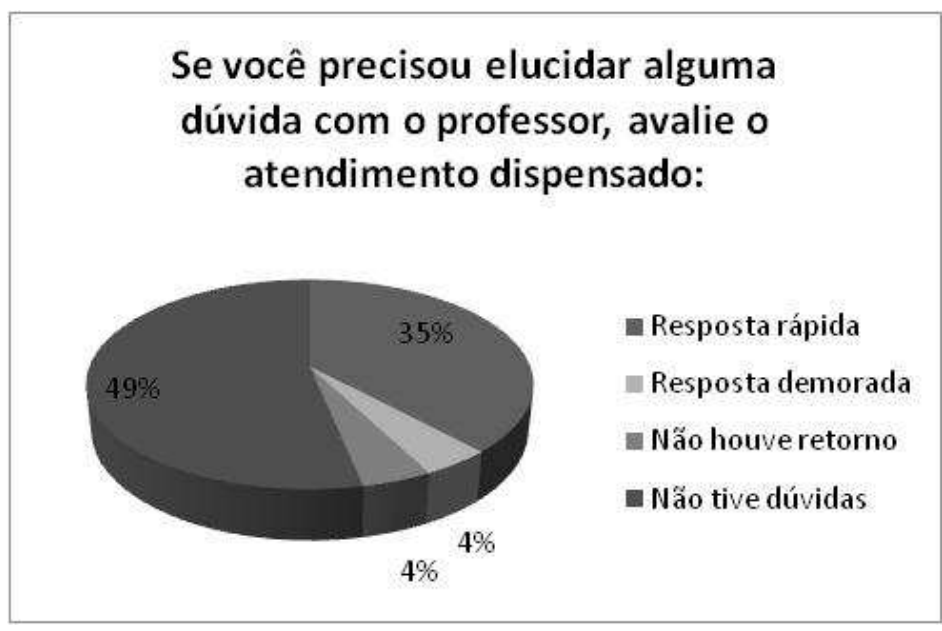

Figura 8: Atendimento do professor

A figura 4 apresenta considerações feitas para o Ambiente Virtual de Aprendizagem (AVA), para a unidade curricular de Matemática Aplicada, em que 30\% dos respondentes apontam para novos links que permitiram uma maior compreensão dos temas, na qual o aluno visitava páginas da enciclopédia eletrônica (wikipédia) e outras ligações ao explorar o conteúdo de matemática. Quase o mesmo percentual (29\% dos respondentes) indicava para uma abordagem similar ao que 
o professor havia proposto, apontando para ambos os casos, um mesmo estilo de pensamento, segundo a concepção de Fleck ${ }^{1}$, é compartilhado entre os que trabalham com Matemática.

Nas figuras 5 e 6, exploram-se as questões referentes ao conteúdo e a linguagem-escrita utilizada pelo professor no Material Didático (disponível ao aprendiz em um livro texto e no AVA). Em 85\% das respostas, os alunos classificam a linguagem utilizada como 'clara' (25\%), 'suficiente' (26\%) e 'adequada' (34\%). O conteúdo, por sua vez, foi dito como 'muito bom' (20\%) e 'bom' (53\%). Cabe ainda ressaltar que muitas informações veiculadas no material didático não foram trabalhadas no ambiente virtual, estavam presentes apenas no texto escrito, com o intuito de subsidiar o trabalho do gestor público em sua atividade (56\% dos alunos da turma 2007/2 já trabalhavam com gestão pública, sendo que $6 \%$ eram da esfera 'federal', $18 \%$ da 'estadual' e $32 \%$ da 'municipal').

Por fim, as figuras 7 e 8 tratam do desempenho e atitude do professor (este pesquisador procurou reforçar a variável diálogo, já que a variável estrutura esteve bem presente no curso) face ao novo contexto de ensino. O IF-SC adota conceitos para avaliar o desempenho dos alunos em seus cursos, assim, optou-se por classificar o desempenho do professor seguindo os mesmos critérios: 'excelente' (40\%), 'proficiente' (31\%) e 'suficiente' (20\%) e 35\% dos que responderam a pesquisa obtiveram uma resposta rápida quando da interação com o professor.

Compartilha-se, aqui, o que se tem utilizado para esta proposta de curso, formas distintas para o aprendizado, entre elas: vídeos, textos, fóruns, links com imagens e exercícios, além de uma série de outras atividades neste cenário das novas tecnologias na educação, também conforme orientação de Kenski (2003) - "adoção de novos hábitos para uma nova tecnologia".

Como ênfase às idéias e recomendações de Kenski, examina-se a seguir uma ferramenta que tem se mostrado de fundamental importância no CSTGP e que possa servir como referência para outras propostas na EAD: o fórum de discussão - uma interface que traz um potencial de maior densidade nas mensagens, tanto por parte do aluno quanto do professor, dependendo do modo como o instrumento é apropriado pelos sujeitos envolvidos.

${ }^{1}$ Ludwik Fleck criou e ancorou sua epistemologia em sua própria experiência (década de 30, século XX); profissional e pesquisador destacado em medicina e sua reflexão na Escola Polonesa de Filosofia da Medicina sobre as práticas dos médicos. Tal escola julgava que os 'fatos científicos' são construídos por comunidades de pesquisadores - segundo os termos de Fleck, coletivos de pensamento. Cada coletivo de pensamento elabora um estilo de pensamento único, composto pelo conjunto de normas, saberes e práticas partilhados por tal coletivo. A incomensurabilidade dos fatos científicos é, para Fleck, uma fonte importante de inovação nas ciências e na sociedade (Delizoicov et al. 2002). 


\section{O Fórum}

$\mathrm{O}$ valor de troca de uma mensagem se constitui a partir do efeito que uma mensagem produz no grupo, quanto maior o número de mensagens vinculadas à mensagem original, maior o valor desta mensagem. $O$ tipo da mensagem refere-se às características do texto postado, que pode ser um comentário, resposta, reflexão, pergunta e outros que podem ou não estar relacionado à continuidade de uma troca.

Para Abreu (2006), a existência do fórum enquanto interface não implica, necessariamente, autoria, cabendo ao professor na EaD, o desafio em buscar formas para que o aluno se coloque mais significativamente na posição de autor. Algumas propostas para a EAD podem estar na busca de dados na Internet para a resolução de situações-problemas, discutindo com os alunos as condições de produção, circulação e recepção de um texto.

A partir, então, de uma concepção da produção de textos, Abreu (2006) salienta que o professor em um curso nesta modalidade educacional possa transcrever do fórum contribuições sobre determinado tema, com os nomes de seus autores e propor a um grupo de alunos que, com essas contribuições, construam outro texto.

Esse movimento reforça os dizeres do grupo como elementos importantes na construção de saber, propiciando uma intensificação da posição do aluno, reforçando, assim, uma relação fundamental no processo de aprendizagem em EaD.

Abreu (2006) aponta que as discussões no fórum podem se transformar em verbetes de um glossário construído coletivamente ou em um texto de divulgação científica, ou ainda em um mapa conceitual disponibilizado para todos os colegas estudarem, entre tantos outros encaminhamentos a serem constituídos pelo professor e seus alunos. Todo esse trabalho com o material do fórum acaba gerando, no seu próprio processo, uma importante ferramenta de interação.

Em uma perspectiva avaliativa e complementar às informações e dados que foram coletados e representados nas figuras anteriores, destacam-se, ainda, algumas falas dos alunos no fórum ${ }^{1}$, logo após o término da disciplina de Matemática e que compuseram a avaliação desta, ressaltando a importância deste espaço de comunicação, interação e autoria presente na modalidade EaD:

${ }^{1}$ O fórum aqui destacado teve como questão proposta: "Qual a sua avaliação sobre a unidade curricular de Matemática Aplicada do CSTGP?". 
"No início do módulo eu encarava a matemática como uma disciplina difícil de entender e aprender, mas no decorrer das aulas fui assimilando a matéria, no início com certa dificuldade. Ao final, para minha surpresa e graças a suas aulas bem elaboradas e magnificamente explicadas, e a interação com os colegas, entendi que a matemática não era um "bicho de Sete cabeças."” (Aluno 1, CSTGP)

“Em vídeo-aula era só prestar atenção, porém teria que anotar os macetes ditos pelo professor. No ambiente se buscou a interação dos assuntos tratados, no meu caso procurei ajuda com professor universitário e com colegas para apreender o manuseio com a máquina calculadora científica." (Aluno 2, CSTGP)

No primeiro depoimento, percebe-se como a unidade curricular de Matemática ainda traz consigo dificuldades e barreiras que são desenvolvidas no ensino presencial tradicional e surge com a presença de um termo designado para a mesma como "bicho de Sete cabeças", que está na instância do inconsciente deste aluno e resulta do modo pelo qual somos afetados pelo discurso de outros. Destaca-se ainda, a importância da mediação do processo feita pelo professor e a necessidade de uma nova forma de interação: aluno-aluno. No segundo, outras interações se estabelecem: aluno-professor, aluno-aluno e aluno-professor universitário - o estudante passa a ser o centro do processo. Na palavra macete, percebe-se a influência de um modo de pensar do ensino presencial tradicional, uma vez que o professor não procurou trabalhar nesta perspectiva.

Outros alunos, apoiados na estrutura disponibilizada para o curso, começam a buscar outras formas de assimilação dos conceitos discutidos na disciplina através de um processo de construção da autonomia, utilizando-se das diversas formas de busca de elementos presentes no Ambiente Virtual:

"O material didático disponibilizado é parcial, mas bem objetivo, cabe ao aluno procurar e estudar outras bibliografias ou materiais disponiveis, inclusive a Internet através da Wikipédia está disponível para todos." (Aluno 3, CSTGP)

Aqui, percebe-se a iniciativa do aluno e a importância do uso do Ambiente Virtual de Aprendizagem, que segundo Abreu (2006) aparece com uma forte significação, tendo a existência de interatividade e o alcance do maior número de leitores, além do desenvolvimento de interfaces que permitam desenvolver mecanismos de extração e análise de dados.

Criar propostas que impliquem o compartilhar das idéias é uma maneira de, colocando o aluno em diálogo, valorizar as diferenças; acreditando com Bakhtin apud Abreu (2006) que "tomamos consciência de nós mesmos através dos outros, de quem recebemos as palavras, as formas, a tonalidade que formam a primeira imagem de nós mesmos". Observa-se, assim, a tentativa de transformação com o fortalecimento da mútua construção nas falas que seguem: 
"A grande dificuldade que vejo é na questão da armação do problema, ou seja, colocar a fórmula correta a partir da pergunta. Pergunto - tem como o professor colocar exemplos resolvidos para cada questão, passo-a-passo?" (Aluno 4, CSTGP)

"O Fórum é uma ferramenta de interação de todos (inclusive do professor). No entanto, sempre esperamos que houvesse uma participação maior dos alunos no esclarecimento de dúvidas dos seus pares....fizemos gravações com exercícios sendo resolvidos, na 2a., 3a. e 4a. semanas colocamos no ar os exercícios resolvidos durante o tira-dúvidas, colocamos "links" no ambiente virtual de outros profissionais que trazem exercícios propostos e resolvidos e, cabe ao aluno, a resolução das atividades propostas - em busca da autonomia, com parcerias e consulta às atividades de outros autores de livros que tratam dos assuntos que abordamos... Bom Estudo e Sucesso!" (Professor, CSTGP)

A orientação do professor, face ao depoimento do Aluno 4, aparece na seleção de conteúdos e oportuniza aos alunos situações concretas de aprendizagem, sendo a mediação fundamental para estabelecer as pontes necessárias entre conhecimento e mídias de forma natural. A autonomia do aprendiz não é algo inerente ao indivíduo, algo que se tentou evidenciar neste depoimento junto ao fórum, pelo contrário, ela contribuiu para modificar o princípio de centralidade da figura do professor no processo educativo e estabelecer o aluno no centro das atividades educacionais.

Com o desenvolvimento e pesquisa efetuados no CSTGP do IF-SC, procurou-se apontar novas perspectivas e rumos para outros projetos nesta modalidade educacional para a instituição, além de definir para acadêmicos, professores e usuários dos cursos de EaD, inseridos em ambientes virtuais de aprendizagem, uma nova forma de enfrentar o desafio imposto pela tecnologia, sem que haja adesão incondicional, ou a oposição radical do ambiente eletrônico, mas, ao contrário, conhecê-los para saber suas vantagens e desvantagens, seus riscos e possibilidades, procurando reconhecer o momento de usá-los e de dispensá-los.

\section{Conclusão}

A teoria da Interação a Distância de Moore não garante que a colaboração e a interação irão desencadear uma reflexão crítica na atividade de alguém. Ferramentas computacionais designadas para o ensino precisam estar alicerçadas em interfaces multimídia/hipermídia e numa pedagogia voltada à busca pela autonomia (construção por parte do usuário). 
A solução de problemas sob orientação, nesta modalidade educacional, além do auxílio do professor e dos demais companheiros, passa por aspectos pedagógicos que orientem o modo como graduar esta assistência, cabendo ao professor vislumbrar a necessidade de alguns estudantes em uma determinada situação. Salomon (1988) orienta que a inclusão do computador no ensino estabelece uma mudança no relacionamento das pessoas com uma determinada tarefa e com o mundo, sendo que os participantes em um ambiente virtual de aprendizagem podem mostrar os ganhos obtidos por uma ferramenta de assistência computadorizada.

A necessidade de equiparar relações de força na EaD para que o aluno persiga a autonomia, antes evidenciada, remete ao professor a urgência em buscar estratégias para que isto possa, de fato, acontecer; assim, o professor passa a ser um pesquisador destas situações e novas interações que surgem no contexto. Parece, ainda, que a disponibilização de cursos à distância tem promovido além da integração dos alunos distantes geograficamente dos centros de pesquisa, também a sua inclusão nestes espaços, possibilitando e promovendo uma atualização continuada de alunos e professores.

Os resultados apresentados neste levantamento exploratório mostraram a oportunidade de acesso aos acadêmicos do CSTGP, permitindo uma maior compreensão dos conteúdos, disponibilizados em um material didático claro e suficiente para as atividades de gestão, segundo relato dos estudantes. Por último, reforçamos as variáveis diálogo e estrutura da proposta de Moore, presentes na prática docente e no curso proposto.

Quando se trata de estratégias, cabe ressaltar a liberdade e criatividade de cada professor na busca de alternativas para estas questões em seu trabalho e no âmbito de sua disciplina, tornando-se um grande desafio a criação de diferentes atividades que inovem no tipo de tarefa que os alunos farão para trabalhar determinados conteúdos; o professor na EaD deve intervir como facilitador da comunicação entre os alunos, o que implica a criação de diferentes metodologias de trabalho para a promoção dessa integração do grupo de sala de aula.

Neste texto, vislumbraram-se novas relações que precisam estar presentes na $\mathrm{EaD}$, sabendo que o professor a distância precisa trabalhar centrado no aluno, no sentido de que necessita conhecer, como dito anteriormente, exatamente o que e como o seu aluno está aprendendo e que dificuldades ele está vivenciando.

Abreu (2006) ressalta que conhecer significa entender a fragmentação da sociedade atual pós-moderna como um valor que não é necessariamente negativo, mas uma fragmentação que evoca para a importância da criação de mais espaços de interlocução social - presencial e online, enfatizando a construção coletiva e cooperativa do conhecimento.

Continuamos a utilizar uma plataforma técnica específica para a EaD que contribua para superar as limitações dos contextos educacionais convencionais, oferecendo novas situações, 
novos desafios, oportunidades de exploração, interatividade e cooperação, sendo a participação do aluno despertada e constantemente alimentada pelas ações do professor.

\section{Referências}

Abreu, Ana S.C. Evaluación en EaD - Valorando el discurso de los alumnos. III Congresso On Line - Observatorio para La Cibersociedad (2006). Disponível em:

http://www.cibersociedad.net/congres2006/gts/comunicacio.php?id=857\&llengua=es. Acesso em: novembro de 2008.

André, Claudio Fernando. A prática da pesquisa e mapeamento informacional bibliográfico apoiados por recursos tecnológicos: impactos na formação de professores. Tese de doutorado apresentada ao programa de pós-graduação em educação. São Paulo: USP, 2009.

Brasil. Ministério da Educação. Programa Universidade Aberta do Brasil. Brasília: MEC, 2009. Delizoicov, Demetrio. et al. Sociogênese do conhecimento e pesquisa em ensino: contribuições a partir do referencial fleckiano. Caderno Brasileiro de Ensino de Física. Universidade Federal de Santa Catarina. Centro de ciências físicas e matemáticas. Departamento de Física. V. 19, n. 1. 2002. Florianópolis.

Freire, Paulo. Pedagogia da Autonomia. Rio de Janeiro: Paz e Terra, 1999.

Holmberg, Borje. Growth and structure of distance education. London: Croom Helm, 1986. Kenski, Vani Moreira. Tecnologias e ensino presencial e a distância. Campinas, SP: Papirus, 2003.

Keegan, Desmond. Foundations of distance education. London and New York: Routledge. 3a. edição, 1996.

Miorim, Maria Ângela. O Ensino de Matemática: Evolução e Modernização. Campinas: 1995. Tese (Doutorado em Educação) - Programa de Pós-Graduação em Educação da Universidade Estadual de Campinas, UNICAMP, Campinas.

Moraes, M. C. O paradigma educacional emergente. São Paulo: Papirus, 1997.

Moore, Michael G. e Kearsley, Greg. Educação a distância: uma visão integrada. Tradução: Roberto Galman. São Paulo: Thomson Learning, 2007.

Pallof, R. e Pratt, K. Construindo comunidades de aprendizagem no ciberespaço: estratégias eficientes para salas de aula on-line. Porto Alegre: ARTMED, 2002.

O aluno virtual: uma guia para trabalhar com estudantes on-line. Porto Alegre:

Artemed, 2004. 
Paulsen, Morten Flate. The Hexagon Of Cooperative Freedom: A Distance Education Theory Attuned to Computer Conferencing. DEOSNEWS, Vol. 3, n.2, Editor: Morten Flate Paulsen, Noruega, 1993.

Peters, Otto. Distance teaching and industrial production: a comparative interpretation in outline. In: Distance Education - International Perspectives. Londres: Croom Helm, 1983.

Salomon, G. Al in reverse: Computer tools that turn cognitive. Journal of Educational Computing Research, 4(2), 123-139, 1988.

Vilarinho, Lúcia R. Anomalias no contexto do Paradigma Tradicional de Ensino. Disponível em: http://www.depotz.net/rEaDarticle.php?article_id=21. Acesso em: junho de 2008.

Alexandre Motta. Instituto Federal de Educação, Ciência e Tecnologia de Santa Catarina. Professor do Instituto Federal de Educação, Ciência e Tecnologia de Santa Catarina. Doutorando do Programa de Pós-graduação em Educação Científica e Tecnológica da Universidade Federal de Santa Catarina. Mestre em Engenharia de Produção pela Universidade Federal de Santa Catarina. amotta@ifsc.edu.br

José André Peres Angotti. Universidade Federal de Santa Catarina. Professor titular de Metodologia e Prática de Ensino de Física e do Programa de PG em Educação Científica e Tecnológica, cursos de Mestrado e Doutorado - Universidade Federal de Santa Catarina. Doutor em Ensino de Ciências/Física - Instituto de Física-IFUSP e Faculdade de Educação - FEUSP da Universidade de São Paulo. angotti@ced.ufsc.br 